ORIGINAL ARTICLE

\title{
Prognostic value of Bax, Bcl-2, p53, and TUNEL staining in patients with radically resected ampullary carcinoma
}

\author{
D Santini, G Tonini, F M Vecchio, D Borzomati, B Vincenzi, S Valeri, A Antinori, F Castri, \\ R Coppola, P Magistrelli, G Nuzzo, A Picciocchi
}

J Clin Pathol 2005;58:159-165. doi: 10.1136/jicp.2004.018887

See end of article for authors' affiliations

Correspondence to: Correspondence to:
Dr D Santini, Campus BioMedico University, Via Emilio Longoni, 83, 00155

Rome, Italy; d.santini@ unicampus. it

Accepted for publication 21 May 2004
Background: There is a lack of data in the literature concerning the identification of potential prognostic factors in ampullary adenocarcinoma.

Aims: To examine the prognostic significance of $\mathrm{Bax}, \mathrm{Bcl}-2$, and $\mathrm{p} 53$ protein expression and the apoptotic index in a large cohort of uniformly treated patients with radically resected ampullary cancer.

Methods: All patients with a pathological diagnosis of ampullary cancer and radical resection were evaluated. Expression analysis for p53, Bax, and Bcl-2 was performed by immunohistochemistry. Apoptotic cells were identified by terminal deoxynucleotidyl transferase mediated dUTP nick end labelling (TUNEL).

Results: Thirty nine tumour specimens from patients with radically resected ampullary adenocarcinoma were studied. A positive significant correlation between Bax and p53 expression was found by rank correlation matrix $(p<0.001)$. A trend towards a positive correlation was found between the apoptotic index and p53 expression $(p=0.059)$. By univariate analysis, overall survival was influenced by Bax expression, p53 expression, and TUNEL staining ( $p=0.001, p=0.01$, and $p=0.03$, respectively). $\mathrm{Bcl}-2$ expression did not influence overall survival in these patients $(p=0.55)$. By multivariate Cox regression analysis, the only immunohistochemical parameter that influenced overall survival was Bax expression ( $p=0.020)$.

Conclusions: These results provide evidence that apoptosis may be an important prognostic factor in patients with radically resected ampullary cancer. This study is the first to assess the clinical usefulness of Bax expression in radically resected ampullary cancer.
$\mathrm{P}$ rimary carcinomas of the extrahepatic biliary system (comprising extrahepatic bile ducts, gall bladder, and ampulla of Vater) are important health problems worldwide, and their management presents great challenges to the hepatobiliary specialist. Carcinoma of the ampulla of Vater is a relatively uncommon tumour, which accounts for approximately $6-7 \%$ of periampullary tumours and $0.2 \%$ of gastrointestinal tract malignancies, ${ }^{1}$ with age standardised incidence rates of 3.8/1000 000 for men and 2.7/1000 000 for women. ${ }^{2}$ Incidence rates have increased over time in men from 1.9 during the period 1976-1980 to 5.9 during the period 1991-1995, whereas in women they have remained stable. ${ }^{2}$ Five year relative survival rates vary from $72.8 \%$ in TNM stage I cancers to $6.6 \%$ in TNM stage IV cancers, and most studies report five year survival rates of $30-50 \%$ in resected patients. ${ }^{3-5}$ The overall rates of resection range between $48.1 \%$ and $82.1 \% .{ }^{25}$ Operative mortality rates range from $1.5 \%$ to $25 \%$, and studies since 1990 have reported mortality rates below $8 \% .^{26-8}$

\begin{abstract}
"There is a need for a better understanding of the biology of ampullary adenocarcinoma and for the identification of potential prognostic factors and clinically relevant molecular targets for treatment"
\end{abstract}

The prognosis for patients with tumours of the ampulla of Vater is better than for other periampullary tumours. The identification of independent prognostic factors in ampullary tumours has been limited by the small numbers of tumours and a lack of pathological review. In a survey from the Memorial Sloan-Kettering Cancer Center, USA, factors significantly correlated with improved survival were resection $(\mathrm{p}<0.01)$, and in resected tumours, negative nodes $(p=0.04)$ and negative margins $(p=0.02)$ independently predicted improved survival. ${ }^{5}$ In that study, when margins, differentiation, and nodal status were examined as covariates by Cox regression, only nodal status and margins were independently correlated with survival. Perineural invasion, histological subtype, and vascular invasion did not reach significance by univariate analysis. In a multivariate analysis performed by Benhamiche et al, stage at diagnosis remained the major prognostic factor $(\mathrm{p}<0.01) .^{2}$ In contrast, several surveys report that the only significant and independent prognostic factor for ampullary cancer is the local spread of the tumour (T stage), whereas the predictive value of tumour grade and lymph nodes metastases is still controversial. ${ }^{9-11}$ Nevertheless, independently from local spread, any cancer stage includes both longterm survivors and short-term survivors, and there is a lack of clinical or histopathological factors able to predict survival.

There is undoubtedly a need for additional prognostic markers, and the molecular anomalies involved in the tumour process may have the potential to represent new significant prognostic factors. Many studies have shown that accumulations of molecular abnormalities of oncogenes, tumour suppressor genes, or growth factors occur during tumorigenesis and tumour progression in ampullary cancer. In several tumour types, such as in breast, lung, colon and gastric cancers, p53 mutations are associated with a poor prognosis. ${ }^{12-15}$ Only a few studies have correlated p53 expression and survival in ampullary tumours. ${ }^{16-19}$ In these

Abbreviations: TBS, Tris buffered saline; TUNEL, terminal deoxynucleotidyl transferase mediated dUTP nick end labelling 


\begin{tabular}{|ll|}
\hline \multicolumn{2}{|l|}{ Table 1 Patients' characteristics } \\
\hline Characteristic & $\mathrm{N}$ \\
\hline Total number & 39 \\
Median (range) age & $62.3(38-78)$ years \\
Sex (M/F) & $20 / 19$ \\
T factor & $10(25.6 \%)$ \\
1 & $17(43.6 \%)$ \\
2 & $11(28.2 \%)$ \\
3 & $1(2.6 \%)$ \\
4 & $25(64 \%)$ \\
N factor & $14(36 \%)$ \\
Negative & $13(33.3 \%)$ \\
Positive & $20(51.3 \%)$ \\
Grading & $6(14.4 \%)$ \\
Well differentiated & $35(89.7 \%)$ \\
Moderately differentiated & $11(28.2 \%)$ \\
Poorly differentiated & $10(25.5 \%)$ \\
Survival & $51(13-102)$ months \\
1 year overall survival & $46(6-100)$ months \\
3 year overall survival & \\
5 year overall survival & \\
Median follow up time (range) & \\
Median overall survival (range) & \\
\hline &
\end{tabular}

reports, p53 overexpression was evaluated during the progression of carcinoma and the relation between p53 expression and prognosis was analysed. In ampullary carcinoma, p53 abnormality occurs during malignant transformation from adenoma and continues during tumour progression in carcinoma, but all studies failed to demonstrate a possible role for p53 in predicting survival. ${ }^{16-19}$ Only Park et al reported that clinical prognosis was worse in patients with p53 overexpression than in those lacking p53 expression. ${ }^{17}$

Some reports aimed to demonstrate a role of proliferating indexes, such as Ki-67, proliferating cell nuclear antigen, the percentage of cells in phase S, and DNA content, in predicting survival. ${ }^{182021}$ In a multivariate analysis, Ajiki et al showed that proliferating cell nuclear antigen expression in ampullary tumours independently contributes to survival $(\mathrm{p}<0.05) .{ }^{16}$ All the other proliferating indexes failed to show a significant correlation with prognosis.

Scarpa et al investigated whether allelic loses (loss of heterozygosity) of chromosomes $17 \mathrm{p}$ and $18 \mathrm{q}$ may be of prognostic value in multivariate survival analysis. ${ }^{22}$ The authors examined 53 ampullary cancers for chromosome $17 \mathrm{p}$ and $18 \mathrm{q}$ loss of heterozygosity using microsatellite markers and DNA from paraffin wax embedded tumours. Multivariate survival analysis included age, sex, tumour size,

Table 2 Immunohistochemical parameters in patients with ampullary adenocarcinoma

\begin{tabular}{lrc}
\hline & N & $\%$ \\
\hline p53 expression & 15 & 38.4 \\
$\quad$ Negative & 23 & 58.9 \\
$\quad$ Positive & 1 & 2.7 \\
$\quad$ Lack & 16 & 41.0 \\
Bcl-2 expression & 22 & 56.3 \\
$\quad$ Negative & 1 & 2.7 \\
$\quad$ Positive & 21 & 53.8 \\
$\quad$ Lack & 18 & 46.2 \\
Bax expression & & \\
$\quad$ Negative & 24 & 61.5 \\
Positive & 15 & 38.5 \\
TUNEL staining & & \\
$\quad \leqslant 10$ & & \\
$>10$ & & \\
\hline TUNEL, terminal deoxynucleotidyl transferase mediated deoxyuridine \\
triphosphate biotin nick end labelling.
\end{tabular}

macroscopic appearance, grade of differentiation, $\mathrm{T}$ stage, lymph node metastasis, and chromosome $17 \mathrm{p}$ and $18 \mathrm{q}$ status. The five year survival rates for chromosome $17 \mathrm{p}$ retention and $17 \mathrm{p}$ loss were $80 \%$ and $7 \%$, respectively. Chromosome $17 \mathrm{p}$ status was an independent prognostic factor among patients with ampullary cancers at the same stage. The same research group ${ }^{23}$ evaluated the role of microsatellite instability in ampullary cancer and showed that replication error negative (absence of microsatellite instability) cancers had a significantly worse prognosis, irrespective of the stage at diagnosis. Therefore, these studies suggested that molecular anomalies might prove useful in discerning prognosis within cancers at the same stage. Several other studies have aimed to evaluate the prognostic role of several molecular parameters (such as cyclooxygenase 2 expression, cyclin Dl, k-ras mutation, intratumorous microvessel density, telomerase activity, and survivin expression) in periampullary cancers. $^{24-29}$ All these molecular factors failed to show a significant correlation with survival, with the exception of cyclin D1. Increased cyclin Dl expression was seen in 17 of 30 carcinomas of the ampulla of Vater, and significantly correlated with tumour cell proliferation and worse clinical outcome. ${ }^{25}$

Thus, there is a need for a better understanding of the biology of ampullary adenocarcinoma and for the identification of potential prognostic factors and clinically relevant molecular targets for treatment. For this reason, we examined for the first time the possible prognostic relevance of Bax, Bcl-2, and p53 protein expression, and of the apoptotic index, in a large cohort of uniformly treated patients with radically resected ampullary cancer.

\section{PATIENTS AND METHODS}

\section{Clinical data and tumour specimen acquisition}

All patients were treated at the Catholic University of the Sacred Heart University and at University Campus BioMedico of Rome, Italy from 1988 to 2002 with radical surgical intent, and only those with no residual disease were considered suitable for our study. Before surgery, all patients were staged by thorax, abdomen, and pelvis computerised tomography scan, by liver palpation, and-when indicatedby intraoperative ultrasound of the liver to exclude the presence of distant metastases. Data on clinical parameters, including sex, age, preoperative assessment of disease state, and type of operative procedure, were gathered retrospectively from patient records. Pathological findings (tumour size and spread, and lymph node status) were obtained from the pathologists' original reports. In addition to the original pathology reports, microscopic findings (tumour type, degree of differentiation, and TNM classification) were re-assessed. Tumours were categorised according to the International Union Against Cancer classification. ${ }^{30}$ Survival was determined from the date of initial surgery to the date of death or the last contact. Follow up data were available for all patients.

\section{Histology}

The formalin fixed, paraffin wax embedded samples were sectioned at $5 \mu \mathrm{m}$ and stained with haematoxylin and eosin. The histological diagnosis was re-examined by two independent pathologists. In addition, the most representative blocks were selected to be cut into new $5 \mu \mathrm{m}$ thick sections for immunohistochemical studies.

\section{Immunohistochemical staining}

Immunohistochemical staining was performed by the streptavidin-biotin method. In brief, sections were dewaxed and antigen retrieval was achieved by steaming the slides for 35 minutes in a $1 \times$ concentration of target retrieval 


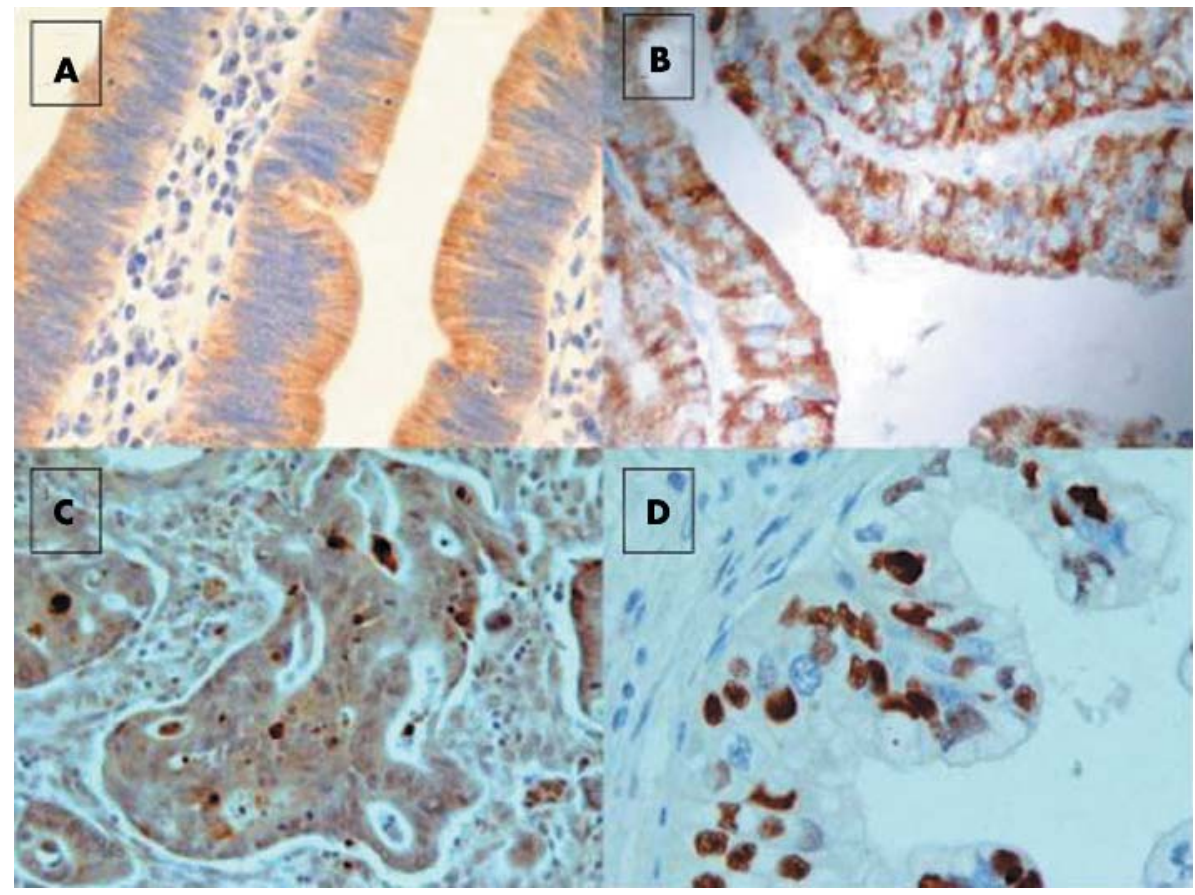

Figure 1 Ampullary adenocarcinoma: (A) intense cytoplasmic positivity for Bax (original magnification, $\times 400)$. (B) Diffuse and pronounced cytoplasmic positivity for $\mathrm{Bcl}-2$ (original magnification, $\times 400$ ). (C) p53 diffuse positivity (original magnification, $\times 400)$. (D) Terminal deoxynucleotidyl transferase mediated deoxyuridine triphosphate biotin nick end labelling nuclear positive staining (original magnification, $\times 400$ ).

solution (Dako Corporation, Carpinteria, California, USA). Endogenous peroxidase was blocked using 3\% hydrogen peroxide solution in phosphate buffered saline for five minutes. The antibodies used were: (1) a monoclonal mouse antibody against the p53 protein (DO7; Dakopatts A $\backslash$, Glostrup, Denmark), which was incubated at a $1 / 50$ dilution at room temperature for one hour; (2) a monoclonal mouse antibody against the Bcl-2 protein (clone 124 Dakopatts $\mathrm{A} \backslash \mathrm{S}$ ), incubated at a $1 / 40$ dilution at room temperature for one hour; and (3) a monoclonal mouse antibody against the Bax protein (clone 2D2; Zymed Laboratories, San Francisco, California, USA), incubated at a $1 / 80$ dilution at room temperature for one hour. After washing three times with Tris buffered saline (TBS), sections were incubated with biotinylated goat antimouselantirabbit immunoglobulin (Dako A\S) for 10 minutes. They were then washed three times with TBS, treated with streptavidin-peroxidase reagent (Dakopatts $\mathrm{A} \backslash \mathrm{S}$ ) for 10 minutes, and then washed again with

Table 3 Correlation between immunohistochemical parameters in patients with radically resected ampullary adenocarcinoma

\begin{tabular}{|c|c|c|c|c|}
\hline & $\mathrm{Bcl}-2$ & TUNEL & Bax & p53 \\
\hline \multicolumn{5}{|l|}{ Bcl-2 } \\
\hline & & $\begin{array}{l}0.099 \\
\text { NS }\end{array}$ & $\begin{array}{l}0.258 \\
\text { NS }\end{array}$ & $\begin{array}{l}0.184 \\
\text { NS }\end{array}$ \\
\hline TUNEL & & & & \\
\hline$\rho$ & 0.99 & & 0.309 & 0.743 \\
\hline$\underset{p q a l u e}{p}$ & NS & & NS & NS \\
\hline \multicolumn{5}{|l|}{ Bax } \\
\hline $\begin{array}{c}\rho \\
\text { p Value } \\
\text { p53 }\end{array}$ & $\begin{array}{l}0.258 \\
\text { NS }\end{array}$ & $\begin{array}{l}0.309 \\
\text { NS }\end{array}$ & & $\begin{array}{l}0.464 \\
<0.001\end{array}$ \\
\hline & 0.184 & 0.059 & 0.743 & \\
\hline $\mathrm{p}$ Value & NS & NS & $<0.001$ & \\
\hline
\end{tabular}

Values in bold are significant.

TUNEL, terminal deoxynucleotidyl transferase mediated deoxyuridine triphosphate biotin nick end labelling
TBS three times. Finally, specimens were incubated in diaminobenzidine for five minutes, followed by counterstaining in Mayer's haematoxylin (Poly Scientific, Bay Shore, New York, USA) for one minute, rinsing twice in deionised water, and dehydrating with ethanol followed by xylene. Semiquantitative evaluation of the immunohistochemical results was performed by two independent observers blinded to patient status.

Table 4 Univariate analysis of survival in patients with radically operated ampullary adenocarcinoma

\begin{tabular}{|c|c|c|c|}
\hline & $\begin{array}{l}\text { Median survival } \\
\text { (months) }\end{array}$ & $95 \% \mathrm{Cl}$ & p Value \\
\hline \multicolumn{4}{|l|}{ Sex } \\
\hline Female & 33.90 & 25.90 to 78.93 & \multirow{2}{*}{0.290} \\
\hline Male & 45.20 & 38.21 to 67.90 & \\
\hline \multicolumn{4}{|l|}{ Age } \\
\hline$<65$ years & 39.74 & 31.25 to 71.93 & \multirow[t]{2}{*}{0.656} \\
\hline$\geqslant 65$ years & 49.60 & 39.89 to 77.10 & \\
\hline \multicolumn{4}{|l|}{ T factor } \\
\hline T1-2 & 50.05 & 43.56 to 82.90 & \multirow[t]{2}{*}{0.135} \\
\hline T3 & 35.50 & 26.00 to 58.78 & \\
\hline \multicolumn{4}{|l|}{$\mathrm{N}$ factor } \\
\hline NO & $57-25$ & 45.65 to 84.56 & \multirow{2}{*}{0.093} \\
\hline $\mathrm{N}+$ & 32.02 & 21.76 to 48.76 & \\
\hline \multicolumn{4}{|l|}{ p53 expression } \\
\hline Negative & 17.34 & 19.00-37.31 & \multirow[t]{3}{*}{0.01} \\
\hline Positive & 66.62 & 51.99 to 81.24 & \\
\hline \multicolumn{3}{|l|}{$\mathrm{Bcl}-2$ expression } & \\
\hline Negative & 58.85 & 40.30 to 77.40 & \multirow[t]{2}{*}{0.55} \\
\hline Positive & 45.80 & 27.99 to 68.01 & \\
\hline \multicolumn{4}{|l|}{ Bax expression } \\
\hline Negative & 28.00 & 8.53 to 54.28 & \multirow[t]{2}{*}{0.001} \\
\hline Positive & 119.98 & 89.04 to 150.93 & \\
\hline \multicolumn{4}{|l|}{ TUNEL staining } \\
\hline$\leqslant 10$ & 44.00 & 8.16 to 79.84 & \multirow[t]{2}{*}{0.03} \\
\hline$>10$ & 121.94 & 84.96 to 158.93 & \\
\hline
\end{tabular}




\section{Scoring and quantification of immunoreactivity}

The immunohistochemical scores for each of the antigens studied were based on published criteria. p53 was considered positive when there was a homogeneous staining pattern with more than $20 \%$ of cells demonstrating nuclear p53 protein accumulation. Bcl-2 staining was evaluated by counting the number of positively stained cells that showed a primarily cytoplasmic localisation of the bcl-2 protein. Bcl-2 was considered to be overexpressed when a homogeneous staining pattern was seen with more than $5 \%$ of cells staining. Bax was considered positive when a homogeneous staining pattern was seen with more than $10 \%$ of cytoplasm staining.

\section{Detection of apoptosis}

Apoptotic cells were identified by the terminal deoxynucleotidyl transferase mediated deoxyuridine triphosphate biotin nick end labelling (TUNEL) method. Dewaxed and rehydrated specimens were incubated in proteinase $\mathrm{K}(40 \mu \mathrm{g} / \mathrm{ml})$ for one hour at $37^{\circ} \mathrm{C}$, and were then treated with $3 \% \mathrm{H}_{2} \mathrm{O}_{2}$ in methanol for 30 minutes at room temperature. After adding equilibration buffer for five minutes at room temperature, the terminal deoxynucleotidyl transferase enzyme was pipetted on to the sections and incubated at $37^{\circ} \mathrm{C}$ for two hours. The reaction was stopped by incubating the sections in stop buffer for 30 minutes at $37^{\circ} \mathrm{C}$. Anti-digoxigenin peroxidase was added to the slides, followed by incubation for 30 minutes at $37^{\circ} \mathrm{C}$. Slides were stained with diaminobenzine for 10 minutes and counterstained with haematoxylin. In total, 500 cells were counted for each specimen. The apoptotic index was defined as follows: apoptotic index $(\%)=$ $100 \times$ apoptotic cells/total cells. We stratified tumour specimens according to TUNEL staining into $\leqslant 10 \%$ or $>10 \%$ stained cells.

\section{Statistical analysis}

Spearman's correlation test was used to assess the relation between the original ordinal data before binary re-categorisations (correlation matrix between immunostaining parameters).

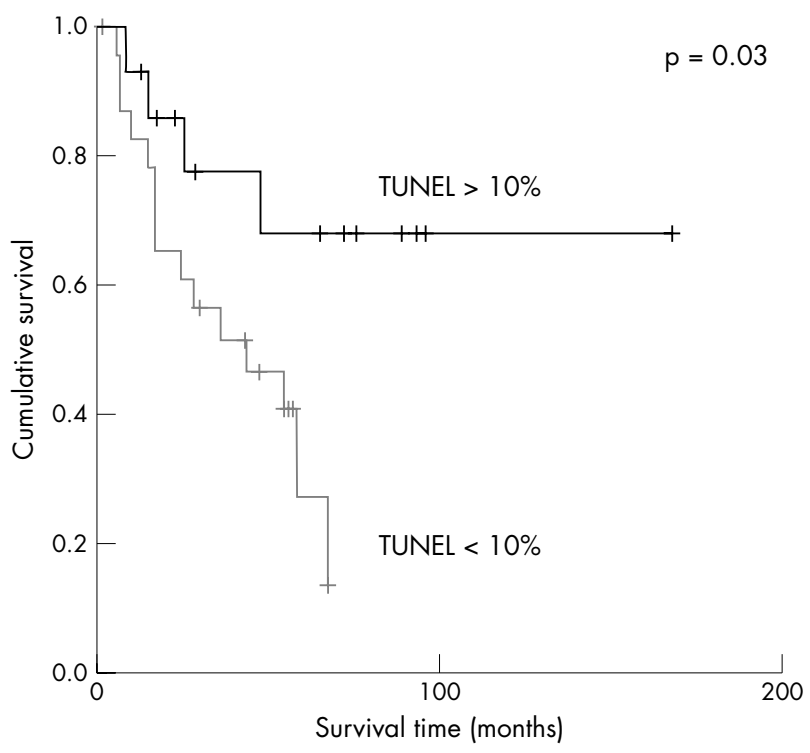

Figure 2 Kaplan-Meier survival curves for patients with radically resected ampullary cancer according to terminal deoxynucleotidyl transferase mediated deoxyuridine triphosphate biotin nick end labelling (TUNEL) staining (>10\% $v \leqslant 10 \%)$.
Univariate survival analysis for each prognostic variable on overall survival was estimated according to the Kaplan-Meier method. ${ }^{23}$ The terminal event was death attributable to cancer or non-cancer causes. The significance of the differences in survival distribution among the prognostic groups was evaluated by the log rank test. ${ }^{24}$ The Cox proportional hazards model was applied to the multivariate survival analysis. ${ }^{25}$ The prognostic variables on overall survival included age, sex, TUNEL staining, and Bcl-2, Bax, and p53 expression.

p Values $<0.05$ was regarded as significant in two tailed tests. SPSS software (version 10.00; SPSS, Chicago, Illinois, USA) was used for statistical analysis.

\section{RESULTS}

\section{Patients' characteristics}

The cohort (table 1) consisted of 39 patients with a pathological diagnosis of cancer of the ampulla (20 men and 19 women) who had undergone radical resection. The median age at diagnosis was 62.3 years (range, 38-78). Table 1 summarises the main histopathological features of the tumours. The median duration of follow up after surgery was 51 months (range, 13-102). The median overall survival was 46 months (range, 6-100) and the one, three, and five year overall survival rates were $89.7 \%, 28.2 \%$, and $25.5 \%$, respectively. After a median follow up of 51 months, 24 patients were alive with no evidence of disease, two patients were alive with recurrence of disease, and 13 patients had died (nine patients died of ampullary carcinoma). Adjuvant radiotherapy and/or chemotherapy for ampullary cancer were not routinely offered in the hospitals involved in our study.

\section{p53, $\mathrm{Bax}, \mathrm{Bcl}-2$, and TUNEL staining}

Table 2 summarises the results from the immunohistochemical analysis of 39 ampullary carcinoma specimens from radically resected patients.

Bax specific immunostaining was cytoplasmic and found to be positive in 21 of the 39 cases (fig 1A). Bcl-2 was expressed in 22 of 39 cases; immunostaining was faint to moderate (fig $1 \mathrm{~B}$ ) and was restricted to the cytoplasm, which is typical for Bcl-2. Stronger staining was seen in peritumorous lymphoid follicles, which were used as an internal

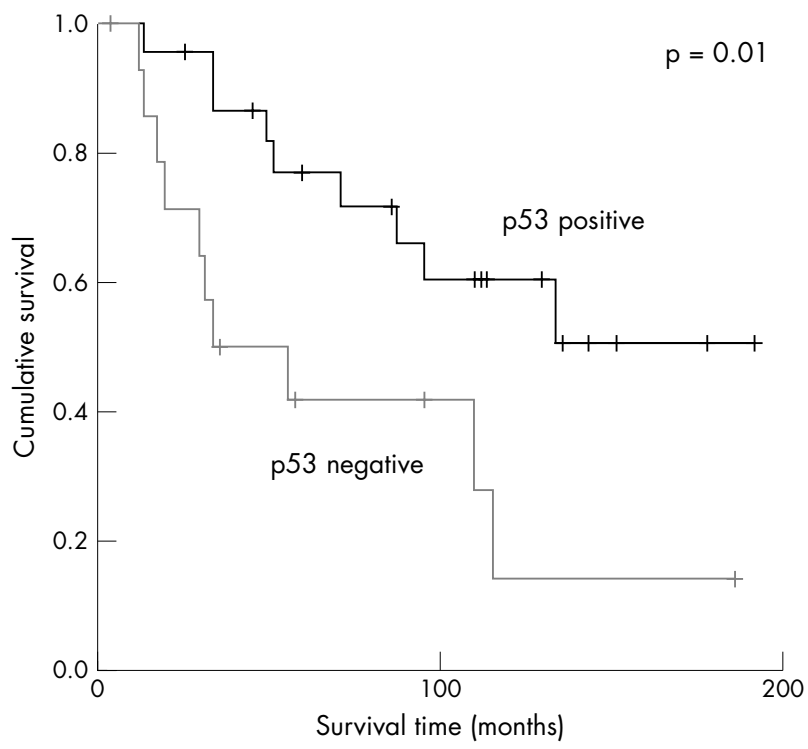

Figure 3 Kaplan-Meier survival curves for patients with radically resected ampullary cancer according to $p 53$ expression ( $p 53$ positive $v$ p53 negative). 
positive control. p53 nuclear expression was present in 15 of the 39 ampullary cancer tissues (fig IC). TUNEL staining was present in more than $10 \%$ of the observed cancer cells in 24 ampullary cancer specimens (fig 1D).

\section{Correlation between immunohistochemical parameters}

Table 3 summarises the correlation between the immunohistochemical results. Using the rank correlation matrix, a positive significant correlation was found between Bax and p53 expression $(p<0.001)$. There was a trend towards a positive correlation between the apoptotic index (evaluated by TUNEL staining) and p53 expression ( $p=0.059$ ). No other significant correlations were recorded between the other immunohistochemical parameters evaluated.

\section{Immunohistochemical and clinicopathological parameters and patient survival}

To determine the prognostic impact of Bax, Bcl-2, and p53 protein expression and TUNEL staining in a univariate survival analysis, patients were stratified according to the dichotomised variables (criteria as stated above) into positive (Bax ${ }^{\text {high }}$, Bcl-2 ${ }^{\text {high }}, \mathrm{p} 53^{\text {high }}$, and TUNEL high apoptotic index versus negative $\left(\mathrm{Bax}^{\text {low }}, \mathrm{Bcl}-2^{\text {low }}, \mathrm{p} 53^{\text {low }}\right.$, and $\mathrm{TUNEL}^{\text {low }}$ apoptotic index .

By univariate analysis, overall survival seemed to be influenced by Bax and p53 expression and TUNEL staining (table 4). In particular, those patients with overexpression of Bax and p53 showed longer overall survival $(p=0.001$ and $\mathrm{p}=0.01$, respectively). The median survival time in patients with high Bax expression was 120 months, compared with only 28 months for those with low Bax expression. The median survival time in patients with high p53 expression was 67 months, compared with only 17 months in those with low p53 expression. Moreover, the median survival time in patients with a high apoptotic index, evaluated by the TUNEL method, was 122 months, compared with 44 months in those with a low apoptotic index $(\mathrm{p}=0.03)$. However, Bcl-2 expression did not influence patient survival (table 4). By univariate analysis, none of the clinicopathological parameters evaluated influenced overall survival (table 4).

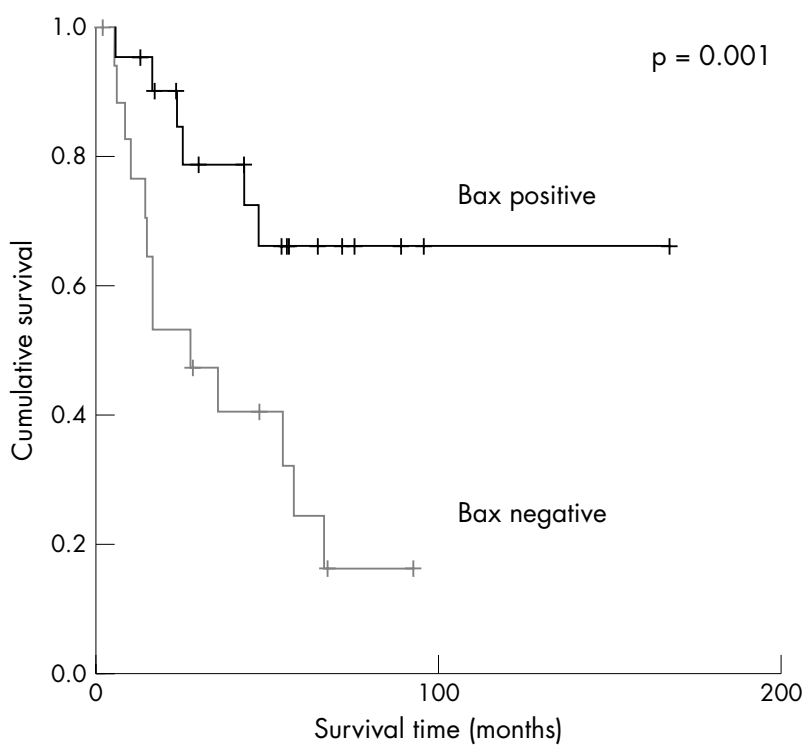

Figure 4 Kaplan-Meier survival curves for patients with radically resected ampullary cancer according to Bax expression (Bax positive $v$ Bax negative).
The Kaplan-Meier method was used to examine the impact of Bax, Bcl-2, and p53 overexpression, and of a high apoptotic index evaluated by the TUNEL method, on overall survival in patients radically resected for ampullary cancer. The Kaplan-Meier survival plots for all patients showed a significant association between either high apoptotic index (fig 2), high p53 expression (fig 3), and high Bax expression (fig 4) and good outcome $(\mathrm{p}=0.03, \mathrm{p}=0.01$, and $p=0.001$, respectively), whereas Bcl-2 expression (fig 5) was not significantly associated with clinical outcome $(\mathrm{p}=0.55)$.

Table 5 summarises the results of the multivariate survival analysis. All variables that reached significance in the univariate survival analysis were incorporated into a multivariate analysis, with disease related survival used as an end point. In this model, only Bax expression retained independent prognostic significance. The relative risk of death in patients with ampullary cancer with high Bax expression was significantly lower than that of patients with low expression $(\mathrm{p}=0.020)$. The other two immunohistochemical parameters significantly associated with prognosis in univariate analysis (p53 expression and TUNEL staining) did not influence the overall survival when evaluated by multivariate analysis as single prognostic factors $(\mathrm{p}=0.756$ and $\mathrm{p}=0.10$, respectively)

\section{DISCUSSION}

To our knowledge, this is the first study to examine the possible prognostic significance of Bcl-2 and Bax expression in patients with radically resected cancer of the ampulla.

The Bcl-2 family, with its antiapoptotic members-Bcl-2, Bcl-xl, Mcl-1, and Al-and death promoting members-Bax, Bcl-xs, Bak, Bad, and Bik-plays a central role in the regulation of cell death. The overexpression of antiapoptotic factors of this gene family, such as Bcl-2, contributes to cancer pathogenesis and may be involved in resistance to cancer treatment. From a functional point of view, Bax plays a central role in regulation and commitment to programmed cell death. Bax counteracts the antiapoptotic effect of Bcl-2 and may directly induce apoptosis. ${ }^{31}{ }^{32}$ The proapoptotic Bax is located in the outer mitochondrial membrane. ${ }^{33}$ Bax overexpression induces mitochondrial permeability

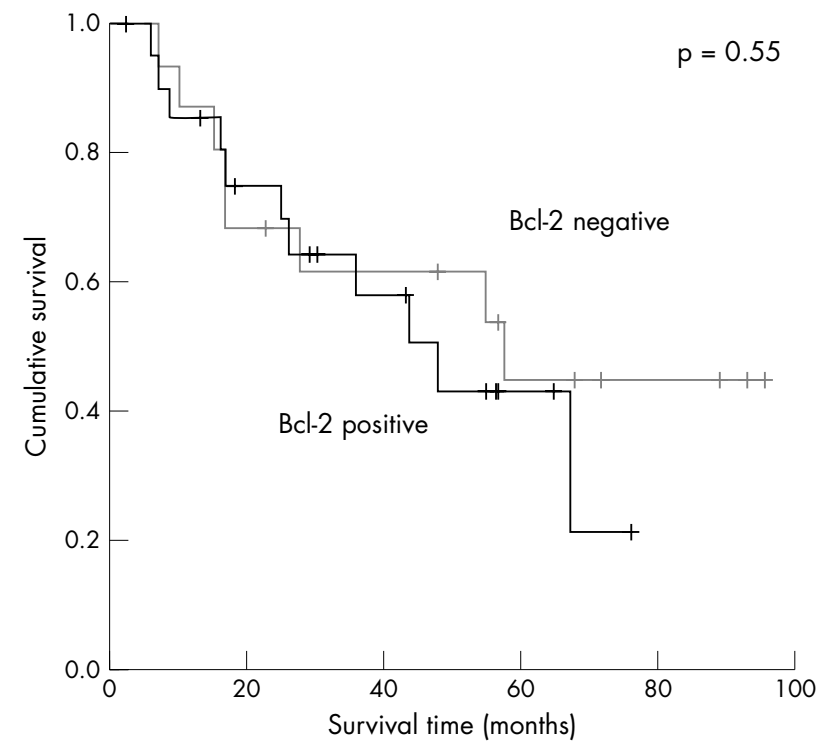

Figure 5 Kaplan-Meier survival curves for patients with radically resected ampullary cancer according to $\mathrm{Bcl}-2$ expression $(\mathrm{Bcl}-2$ positive $v$ $\mathrm{BCl}-2$ negative). 
Table 5 Multivariate analysis of survival in patients with radically operated ampullary adenocarcinoma

\begin{tabular}{|c|c|c|c|}
\hline & Relative risk & $95 \% \mathrm{Cl}$ & p Value \\
\hline \multicolumn{4}{|c|}{ p53 expression } \\
\hline Negative & 1 & - & \multirow{2}{*}{0.756} \\
\hline Positive & 0.915 & 0.467 to 1.561 & \\
\hline \multicolumn{4}{|c|}{ Bax expression } \\
\hline Negative & 1 & - & \multirow{2}{*}{0.020} \\
\hline Positive & 0.371 & 0.210 to 0.863 & \\
\hline \multicolumn{4}{|c|}{ TUNEL staining } \\
\hline Positive & 1 & - & \multirow{2}{*}{0.10} \\
\hline Negative & 0.564 & 0.333 to 1.316 & \\
\hline
\end{tabular}

$\mathrm{Cl}$, confidence interval; TUNEL, terminal deoxynucleotidyl transferase mediated deoxyuridine triphosphate biotin nick end labelling. transition, which leads to the release of cytochrome c. ${ }^{34}$ Cytochrome $\mathrm{c}$ induces autocleavage of caspase 9, and the subsequent activation of the effector caspase $3 .{ }^{35}$ Cleavage of caspase substrates such as poly-(adenosine $5^{\prime}$-diphosphate ribose) polymerase and DNA fragmentation factor, ${ }^{36}$ leads to the degradation of chromosomal DNA and irreversibly triggers the execution phase of apoptosis. There is increasing evidence for the prognostic value of Bax in several tumour types, such as breast cancer, ${ }^{37}$ ovarian cancer, ${ }^{38}$ diffuse aggressive non-Hodgkin lymphoma, ${ }^{39}$ oesophageal squamous cell carcinoma, ${ }^{40}$ pancreatic cancer ${ }^{41}$ and small cell carcinoma of the lung. ${ }^{42}$ The prognostic role of Bax in cancer of the ampulla is unknown and data are still lacking in the literature.

"Bax, Bcl-2, and the apoptotic index had a significant impact on overall survival in our cohort of patients"

p53 is known to play a central role in sensing and signalling for growth arrest and apoptosis in cells with DNA damage. ${ }^{43}$ Wild-type p53 is upregulated after cellular stress such as DNA damage or hypoxia. It mediates pathways that lead to Gl arrest and may allow mechanisms for DNA repair or induces apoptotic pathways that drive cells to commit suicide. Both Bcl-2 and Bax are transcriptional targets for p53, which induces cell cycle arrest or apoptosis in response to DNA damage. ${ }^{44}$ As previously reported, few studies have correlated p53 expression with survival in ampullary tumours. ${ }^{16-19}$ p53 abnormality occurs during malignant transformation from adenoma and continues during tumour progression in carcinoma, but all studies failed to demonstrate a possible role of p53 in predicting survival. ${ }^{16-19}$ We have shown for the first time a significant association between high p53 expression and good clinical outcome. Moreover, this is the first study to examine the possible prognostic significance of $\mathrm{Bax}$ and $\mathrm{Bcl}-2$ protein expression and the apoptotic index in patients with radically resected ampullary cancer. We clearly demonstrated a significant prognostic role for these molecular factors in ampullary cancer. Bax, Bcl-2, and the apoptotic index had a significant impact on overall survival in our cohort of patients. Moreover, the positive significant correlation between Bax and p53 expression suggests that, in our patients with ampullary cancer, apoptosis is p53 dependent, as has previously been reported for other types of cancer. ${ }^{45}$ Finally, when all variables that reached significance in the univariate survival analysis were incorporated into a multivariate analysis, only Bax expression retained independent prognostic significance. The calculated relative risk of death in patients with ampullary cancer with high Bax expression was significantly lower $(0.371 ; p=0.020)$. The results of our
Take home messages

- We provide evidence that apoptosis may be an important prognostic factor in patients with radically resected ampullary cancer

- This study, the first to assess the clinical usefulness of $\mathrm{Bax}$ and $\mathrm{Bcl}-2$ expression in radically resected ampullary cancer, showed that high expression of Bax is associated with longer survival

- The positive significant correlation between Bax and p53 expression suggests that, in our patients with ampullary cancer, apoptosis is p53 dependent, as has previously been reported for other types of cancer

study provide evidence that apoptosis may be an important prognostic factor in patients with radically resected ampullary cancer. To the best of our knowledge, our present study is the first one to assess the clinical usefulness of Bax expression in radically resected ampullary cancer. Knowledge of those factors that have an independent influence on prognosis is crucial in the development and interpretation of prospective randomised trials in which patients are stratified according to these prognostic determinants. In conclusion, it should be kept in mind that these groups were identified retrospectively, but our results show that we may be coming closer to a combined clinical and molecular substaging of patients within single, classic disease stages.

\section{ACKNOWLEDGMENTS}

We would like to thank Mrs R Macrina for her linguistic revision of the manuscript.

\section{Authors' affiliations}

D Santini, G Tonini, D Borzomati, B Vincenzi, S Valeri, R Coppola, University Campus Bio-Medico University, Via Emilio Longoni, 83, 00155 Rome, Italy

F M Vecchio, A Antinori, F Castri, P Magistrelli, G Nuzzo, A Picciocchi, Catholic University of the Sacred Heart, 800168 Rome, Italy

\section{REFERENCES}

1 Brennan MF. Surgical management of peripancreatic cancer. In: Bland KI, Karakousis CP, Copeland EM, eds. Atlas of surgical oncology. Philadelphia: WB Saunders Company, 1995:473-85.

2 Benhamiche AM, Jouve JL, Manfredi S, et al. Cancer of the ampulla of Vater: results of a 20-year population-based study. Eur J Gastroenterol Hepatol 2000; 12:75-9

3 Trede M, Schwall G, Saeger HD. Survival after pancreatoduodenectomy. 118 consecutive resections without an operative mortality. Ann Surg 1990;211:447-58.

4 Martin FM, Rossi RL, Dorrucci V, et al. Clinical and pathologic correlations in patients with periampullary tumors. Arch Surg 1990;125:723-6.

5 Howe JR, Klimstra DS, Moccia RD, et al. Factors predictive of survival in ampullary carcinoma. Ann Surg 1998;228:87-94

6 Allema JH, Reinders ME, van Gulik TM, et al. Results of pancreaticoduodenectomy for ampullary carcinoma and analysis of prognostic factors for survival. Surgery 1995;117:247-53.

7 Allema JH, Reinders ME, van Gulik TM, et al. Prognostic factors for survival after pancreaticoduodenectomy for patients with carcinoma of the pancreatic head region. Cancer 1995;75:2069-76.

8 van Geenen RC, van Gulik TM, Offerhaus GJ, et al. Survival after pancreaticoduodenectomy for periampullary adenocarcinoma: an update. Eur J Surg Oncol 2001;27:549-57.

9 Klempnaver J, Ridder GJ, Pichlmayr R. Prognostic factors after resection of ampullary carcinoma: multivariate survival analysis in comparison with ductal cancer of the pancreatic head. Br J Surg 1995;82:1686-91.

10 Talamini MA, Moesinger RC, Pitt HA. et al, Adenocarcinoma of the ampulla of Vater. A 28-year experience. Ann Surg 1997;225:590-9, discussion 599-600.

11 Dorandeu A, Raoul JL, Siriser F, et al. Carcinoma of the ampulla of Vater: prognostic factors after curative surgery: a series of 45 cases. Gut 1997;40:350-5. 
12 Thompson AM, Anderson TJ, Condie A, et al. p53 allele losses, mutations and expression in breast cancer and their relationship to clinico-pathological parameters. Int J Cancer 1992;50:528-32.

13 Quinlan DC, Davidson AG, Summers CL, et al. Accumulation of p53 protein correlates with a poor prognosis in human lung cancer. Cancer Res 1992;52:4828-31.

14 Hamelin R, Laurent-Puig P, Olschwang S, et al. Association of p53 mutations with short survival in colorectal cancer. Gastroenterology 1994; 106:42-8.

15 Martin HM, Filipe MI, Morris RW, et al. p53 expression and prognosis in gastric carcinoma. Int J Cancer 1992;50:859-62.

16 Ajiki T, Kamigaki T, Hasegawa Y, et al. Proliferating cell nuclear antigen, p53, and c-erbB-2 expression in relation to clinicopathological variables and prognosis in cancer of the ampulla of Vater. Hepatogastroenterology 2001:48:1266-70.

17 Park SH, Kim Yl, Park YH, et al. Clinicopathologic correlation of p53 protein overexpression in adenoma and carcinoma of the ampulla of Vater. World J Surg 2000;24:54-9.

18 Takashima M, Ueki T, Nagai E, et al. Carcinoma of the ampulla of Vater associated with or without adenoma: a clinicopathologic analysis of 198 cases with reference to $\mathrm{p} 53$ and $\mathrm{Ki}-67$ immunohistochemical expressions. Mod Pathol 2000;13:1300-7.

19 Zhu L, Kim K, Domenico DR, et al. Adenocarcinoma of duodenum and ampulla of Vater: clinicopathology study and expression of p53, c-neu, TGFalpha, CEA, and EMA. J Surg Oncol 1996:61:100-5.

20 Ajiki T, Kamigaki T, Hasegawa Y, et al. Proliferating cell nuclear antigen, p53, and c-erbB-2 expression in relation to clinicopathological variables and prognosis in cancer of the ampulla of Vater. Hepatogastroenterology 2001:48:1266-70.

21 Crucitti A, Masetti R, Breccia C, et al. Ampullary carcinoma: prognostic significance of ploidy, cell-cycle analysis and proliferating cell nuclear antigen (PCNA). Hepatogastroenterology 1999;46:1187-91.

22 Scarpa A, Di Pace C, Talamini G, et al. Cancer of the ampulla of Vater: chromosome 17p allelic loss is associated with poor prognosis. Gut 2000:46:842-8

23 Achille A, Biasi MO, Zamboni G, et al. Cancers of the papilla of Vater: mutator phenotype is associated with good prognosis. Clin Cancer Res 1997:3:1841-7.

$24 \mathrm{Kim}$ HJ, Sohn TS, Lee KT, et al. Expression of cyclooxygenase-2 and its correlation with clinicopathologic factors of ampulla of Vater cancer. J Korean Med Sci 2003;18:218-24.

25 Yamazaki K, Hanami K, Nagao T, et al. Increased cyclin D1 expression in cancer of the ampulla of Vater: relevance to nuclear beta catenin accumulation and k-ras gene mutation. Mol Pathol 2003;56:336-41.

26 Howe JR, Klimstra DS, Cordon-Cardo C, et al. K-ras mutation in adenomas and carcinomas of the ampulla of Vater. Clin Cancer Res 1997;3:129-33.

27 Khan AW, Dhillon AP, Hutchins R, et al. Prognostic significance of intratumoural microvessel density (IMD) in resected pancreatic and ampullary cancers to standard histopathological variables and survival. Eur J Surg Oncol 2002;28:637-44.
28 Balcom JH 4th, Keck T, Warshaw AL, et al. Telomerase activity in periampullary tumors correlates with aggressive malignancy. Ann Surg $2001 ; 234: 344-50,344-50$, discussion 350-1.

29 Sarela Al, Verbeke CS, Ramsdale J, et al. Expression of survivin, a novel inhibitor of apoptosis and cell cycle regulatory protein, in pancreatic adenocarcinoma. Br J Cancer 2002;86:886-92.

30 Sobin LH, Wittekind C. TNM classification of malignant tumours: UICC International Union Against Cancer, 5th ed. New York: NY, Wiley-Liss, 2002.

31 Zha H, Reed JC. Heterodimerization-independent functions of cell death regulatory proteins $\mathrm{Bax}$ and $\mathrm{Bcl}-2$ in yeast and mammalian cells. J Biol Chem 1997:272:31482-8

32 Xiang J, Chao DT, Korsmeyer SJ. BAX-induced cell death may not require interleukin 1 beta-converting enzyme-like proteases. Proc Natl Acad Sci U S A 1996:93:14559-63.

33 Schlesinger PH, Gross A, Yin XM, et al. Comparison of the ion channel characteristics of proapoptotic BAX and antiapoptotic BCL-2. Proc Natl Acad Sci U S A 1997;94:11357-62.

34 Pastorino JG, Chen ST, Tafani M, et al. The overexpression of Bax produces cell death upon induction of the mitochondrial permeability transition. J Biol Chem 1998:273:7770-5.

35 Jürgensmeier JM, Xie ZH, Deveraux $Q$, et al. Bax directly induces release of cytochrome c from isolated mitochondria. Proc Natl Acad Sci U S A 1998;95:4997-5002.

36 Liu $\mathbf{X}$, Zou H, Slaughter C, et al. DFF, a heterodimeric protein that functions downstream of caspase-3 to trigger DNA fragmentation during apoptosis. Cell 1997;89:175-84

37 Krajewski S, Blomqvist C, Franssila K, et al. Reduced expression of proapoptotic gene BAX is associated with poor response rates to combination chemotherapy and shorter survival in women with metastatic breast adenocarcinoma. Cancer Res 1995;55:4471-8.

38 Tai YT, Lee S, Niloff $E$, et al. BAX protein expression and clinical outcome in epithelial ovarian cancer. J Clin Oncol 1998;16:2583-90.

39 Gascoyne RD, Krajewska M, Krajewsky S, et al. Prognostic significance of BAX protein expression in diffuse aggressive non-Hodgkin's lymphoma. Blood 1997; $90: 3173-8$

40 Sturm I, Petrowsky H, Volz R, et al. Analysis of p53/BAX/p16/ink4a/ CDKN2) in esophageal squamous cell carcinoma: high BAX and pl6(ink4a/ CDKN2) identifies patients with good prognosis. J Clin Oncol 2001;19:2272-81.

41 Friess $\mathrm{H}$, Lu Z, Graber HU, et al. Bax, but not bcl-2, influences the prognosis of human pancreatic cancer. Gut 1998;43:414-21.

42 Huang $\mathrm{Cl}$, Taki T, Higashiyama $\mathrm{M}$, et al. pl6 protein expression is associated with a poor prognosis in squamous cell carcinoma of the lung. $\mathrm{Br} J$ Cancer 2000;82:374-80

43 Lane DP. Cancer: p53, guardian of the genome. Nature 1992;358:15-16.

44 Basu A, Haldar S. The relationship between Bcl2, Bax and p53: consequences for cell cycle progression and cell death. Mol Hum Reprod 1998;4:1099-109.

45 Miyashita T, Reed JC. Tumor suppressor p53 is a direct transcriptional activator of the human bax gene. Cell 1995;80:293-9. 